\title{
Sleep deprivation and Pavlovian fear conditioning
}

\author{
Denise J. Cai, ${ }^{1,3}$ Tristan Shuman, ${ }^{1}$ Elizabeth M. Harrison, ${ }^{1}$ Jennifer R. Sage, ${ }^{1}$ and Stephan \\ G. Anagnostaras ${ }^{1,2}$ \\ ${ }^{1}$ Molecular Cognition Laboratory, Department of Psychology, University of California, San Diego, California 92093-0109, USA; \\ ${ }^{2}$ Program in Neurosciences, University of California, San Diego, California 92093-0109, USA
}

\begin{abstract}
Sleep has been suggested to play a role in memory consolidation. Prior rodent studies have used sleep deprivation to examine this relationship. First, we reexamined the effects of sleep deprivation on Pavlovian fear conditioning. We found that the deprivation method itself (i.e., gentle handling) induced deficits independent of sleep. Second, we examined an alternative method of sleep deprivation using amphetamine and found that this method failed to induce amnesia. These data indicate that sleep deprivation is a problematic way to examine the role of sleep in memory consolidation, and an alternative paradigm is proposed.
\end{abstract}

A growing body of evidence suggests that sleep plays a role in memory consolidation, although the exact nature of this relationship remains unclear. In human studies, sleep-deprived subjects typically have impaired memory retention (Bonnet and Arand 1995; Arnold et al. 1997; Carter et al. 2003). This impairment, however, may be caused by non-sleep factors associated with the method of deprivation, such as stress. Sleep deprivation in humans can cause physiological stress, marked by stomach ulcers and elevated cortisol (Mullington et al. 2009), that could interfere with memory (Sapolsky 2004). Moreover, the fatigue associated with sleep deprivation may produce performance deficits, even after a night of recovery sleep. One recent imaging study found that it takes more than one night of recovery sleep for the human brain to return to normal use of its neural network (McKenna et al. 2009). This suggests that sleep deprivation produces changes in brain state that could impair normal consolidation or retrieval.

To avoid these confounds, many researchers have turned to a more naturalistic method of allowing normal sleeping or waking periods to pass between training and test. Typically, a sleep group is trained at night and tested in the morning after a period of sleep, while an awake group is trained in the morning and tested in the evening after an equivalent delay interval. Recall is often better after a night of sleep (Ellenbogen et al. 2006; Nishida et al. 2009). This alternative method successfully circumvents the confounds of sleep deprivation; however, most animal studies continue to use sleep deprivation to explore the effects of sleep on memory consolidation.

Early studies deprived animals of sleep by placing them on a rotating disk or on top of an inverted partially submerged flower pot over water (Dement et al. 1968; Van Hulzen and Coenen 1979; Murison et al. 1982; Rechtschaffen et al. 1989). These methods of sleep deprivation have been highly criticized for their potentially stress-inducing side-effects (Horne and McGrath 1984; Smith 1985; Vertes and Eastman 2000). Recent sleep deprivation studies have utilized a gentler approach—handling the animals during sleep. However, even this handling method has been shown to induce stomach ulcerations (Murison et al. 1982) and increased levels of glucoccorticoids, which can impair cognition (Plihal et al. 1996; Sapolsky 2004). In fact, long-term potentiation is diminished in area CA1 from sleep-deprived rats, and this correlates with

\footnotetext{
${ }^{3}$ Corresponding author.
}

E-mail dcai@ucsd.edu; fax (858) 534-7190.

Article is online at http://www.learnmem.org/cgi/doi/10.1101/lm.1515609. increased corticosterone levels (Campbell et al. 2002). Finally, because sleep is a homeostatic drive, the buildup of sleep debt is likely stressful in itself (Roehrs et al. 1990; Carter et al. 2003; Anderson and Horne 2008). Thus, while the rodent sleep deprivation literature suggests that sleep is important for memory consolidation, it is unclear whether these effects are caused by the absence of sleep or by non-sleep-related consequences of deprivation.

An ideal task to examine the relationship between sleep and memory consolidation is Pavlovian fear conditioning, in which a tone is paired with a shock in a distinct context. After a single pairing, rodents will exhibit fear when presented with the training tone, or when returned to the training environment. This latter phenomenon, known as contextual fear conditioning, has garnered considerable interest because it is hippocampus-dependent and has become a prominent rodent model of declarative memory (Anagnostaras et al. 1999, 2000, 2001, 2002a). Pavlovian fear conditioning is well-suited for the examination of the role of sleep and memory because it is rapidly acquired and can dissociate between hippocampus-dependent and -independent memory. Consistent with human declarative memory, contextual fear gradually becomes independent of the hippocampus, as this memory is consolidated to neocortical structures (Maren et al. 1998; Anagnostaras et al. 1999; Frankland et al. 2004; Quinn et al. 2008). This consolidation process is thought to reflect coordinated activity whereby fast-changing connections in the hippocampus initially subserve the memory, and over time entrain slow-changing connections in the neocortex, at which time the hippocampus is no longer necessary to maintain the memory (Squire and Alvarez 1995). In contrast, tone (cued) fear is independent of the hippocampus (Anagnostaras et al. 2001), yet both contextual and cued fear memory depend on the amygdala for the animal's lifetime (Gale et al. 2004).

Graves and colleagues examined the effects of sleep deprivation on Pavlovian fear conditioning (Graves et al. 2003). They found that sleep deprivation impaired performance only when administered immediately following training. Several issues make their data difficult to interpret. First, all three groups (non-sleepdeprived, sleep deprived immediately after training, and sleep deprived $5 \mathrm{~h}$ after training) were trained and tested in the main sleep period (Fig. 1A). Training the animals during their main sleep period likely induced sleep deprivation in all groups, including the Non-Sleep-Deprived group. Moreover, testing mice during this phase is equally problematic (Chaudhury and Colwell 2002). Second, the animals were tested within $24 \mathrm{~h}$ of the sleep deprivation, 


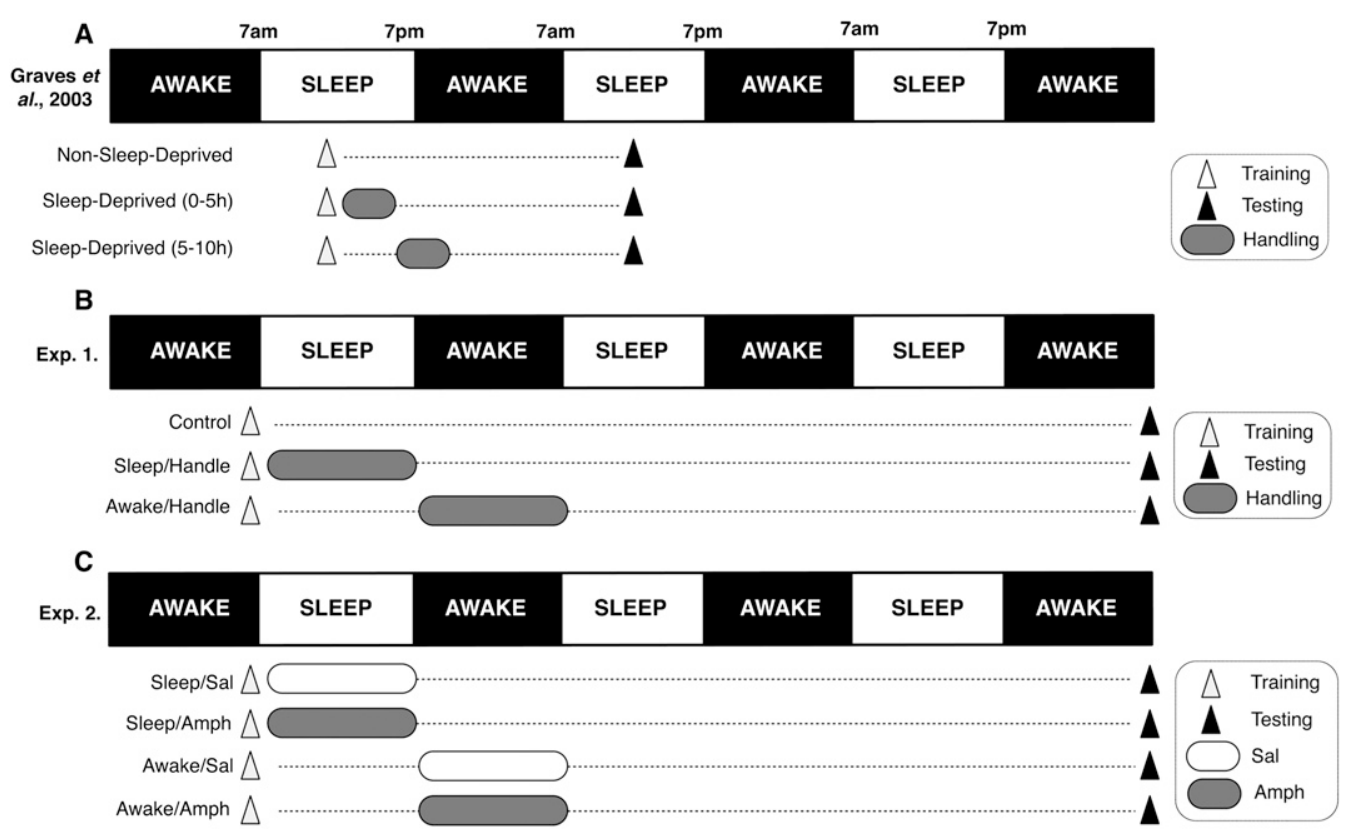

Figure 1. (A) Schematic timeline of Graves et al. (2003). Mice were trained at 12 p.m., $5 \mathrm{~h}$ into the main sleep phase, and tested $24 \mathrm{~h}$ later. The NonSleep-Deprived group returned to their home cage immediately after training. The Sleep-Deprived $(0-5 h)$ group was handled for $5 \mathrm{~h}$, beginning immediately post-training. The Sleep-Deprived $(5-10 \mathrm{~h}$ ) group was handled for $5 \mathrm{~h}$, starting at 5 p.m., which was $5 \mathrm{~h}$ after training. (B) Schematic timeline of experiment 1 . Mice were trained at 6 a.m., $1 \mathrm{~h}$ prior to their main sleep phase, and tested $72 \mathrm{~h}$ later to allow for sufficient recovery sleep. The Control group returned to their home cage immediately after training. The Sleep/Handle (Sleep-Deprivation) group was handled for $12 \mathrm{~h}$ (the entire sleep phase), beginning immediately post-training. The Awake/Handle group was handled for $12 \mathrm{~h}$ (the entire awake phase), starting $12 \mathrm{~h}$ following training. (C) Schematic timeline of experiment 2. Mice were trained at 6 a.m., $1 \mathrm{~h}$ prior to their main sleep phase, and tested $72 \mathrm{~h}$ later. The Sleep/Sal group was administered saline immediately post-training and $4 \mathrm{~h}$ later. The Sleep/Amph group was sleep-deprived with $8 \mathrm{mg} / \mathrm{kg}$ (i.p.) of amphetamine immediately post-training and $4 \mathrm{~h}$ later. To control for non-sleep-related effects of amphetamine, the Awake/Sal and Awake/Amph groups were administered saline and amphetamine, respectively, $12 \mathrm{~h}$ and $16 \mathrm{~h}$ post-training.

and performance deficits could result from residual fatigue (Rickard et al. 2008; McKenna et al. 2009). Third, there was no adequate control for the sleep deprivation method used, to demonstrate that it was lack of sleep per se that produced the deficit. Therefore, it is still unclear whether the impairments observed with sleep deprivation are due to the lack of sleep or to other nonsleep-related effects.

In experiment 1 , we expanded on the findings of Graves et al. (2003) and used a design that addresses the confounds listed above, to reexamine how sleep deprivation by gentle handling, and the handling manipulation itself, affects memory consolidation. In experiment 2 , we examined an alternative method of sleep deprivation by administering two spaced injections of a moderately high dose of amphetamine.

\section{Subjects}

Sixty-seven (Exp 1) and 65 (Exp 2) hybrid C57BL/6Jx129T2SvEms/ $\mathrm{J}$ (Crawley et al. 1997; Matynia et al. 2008) male and female mice (Jackson Laboratory, Bar Harbor, ME) were balanced across groups. Mice were entrained to a 12:12 light/dark cycle. All animals were handled five times for $1 \mathrm{~min}$ each in both the dark and light phases.

\section{Experiment 1}

Pavlovian fear conditioning was conducted $1 \mathrm{~h}$ before the primary sleep period (Fig. 1B). Mice were placed in a fear conditioning chamber (see Conditioning Contexts in Cai et al. 2009; Wood and Anagnostaras 2009) and, after a 2-min baseline, received one tone (2.8-kHz, 30-sec, 85-dB) footshock (2-sec, 1.0-mA, AC) pairing; they remained there for an additional 5 min extended post-shock freezing test. Mice then received one of three treatments. The Control group was undisturbed in their home cage until testing 72 $\mathrm{h}$ later. The Sleep/Handle group was sleep deprived throughout the entire subsequent sleep phase, by gentle handling. Specifically, experimenters continuously observed the animals (with dim red head-mounted LED lights) and gently prodded the mouse whenever it was falling asleep. Sleep was defined as a lack of motion (except that required for respiration) and the eyes closed. To control for non-sleep-related effects from handling, the Awake/ Handle group was handled throughout the entire subsequent awake period, beginning $12 \mathrm{~h}$ after training. This group was gently handled once every $15 \mathrm{~min}$ during their awake phase. Freezing was measured according to an automated algorithm (Wood and Anagnostaras 2009). A one-way ANOVA revealed no group differences during training $\left(F_{(2,64)}<1\right.$, n.s.), and all groups exhibited significant learning $\left(F_{(9,64)}=17.5, P<0.001\right.$; Fig. 2 A $)$.

Contextual fear was examined $72 \mathrm{~h}$ after training by returning them to the conditioning chamber for $5 \mathrm{~min}$ (Fig. 2B). Handling during either the awake (Awake/Handle) or sleep phase (Sleep/Handle) impaired contextual fear memory compared with controls. A univariate ANOVA found group differences during the context test $\left(F_{(2,64)}=4.24, P=0.02\right)$, and post-hoc analysis using Fisher's PLSD revealed significant differences $(P<0.05)$ between the Control group and both Handle groups, which did not differ from one another $(P>0.8$, n.s. $)$.

Thirty minutes following the context test, mice were placed in a novel context and given a 5-min cued fear test. After a 2-min baseline period, the training tone was presented three times without shock. Mice that were handled during the sleep phase (Sleep/Handle) were significantly impaired compared with Control mice, while mice that were handled during the awake phase 

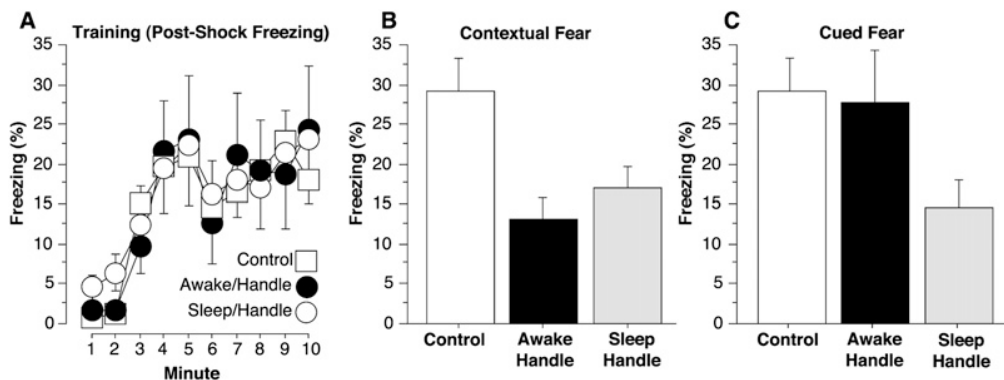

Figure 2. (A) Training: After a 2-min habituation period, mice were given one tone-shock pairing and were left in the chambers for a total of $10 \mathrm{~min}$. Freezing (mean percent time \pm SEM) is depicted for each minute of the training session. All groups exhibited robust learning, and there were no group differences. (B) Contextual Fear: Seventy-two hours post-training, mice were given a 5-min contextual fear test, and freezing (mean percent time \pm SEM) for the 5-min test is depicted. Both the Awake/ Handle and Sleep/Handle groups are impaired compared with the Control group. (C) Cued Fear: Thirty minutes after the context test, mice were brought to a novel context for a 5-min cued fear test. After a 2-min baseline period, the training tone was presented three times across $3 \mathrm{~min}$. Cued fear is depicted as freezing (mean percent time \pm SEM) during the baseline subtracted from the average of freezing to the three tones. The Sleep/Handle group had a deficit compared with the Control group, while there were no differences between Awake/Handle and Control groups.

(Awake/Handle) showed no deficit (Fig. 2C). Freezing during the 2-min baseline was subtracted from the average freezing to the three tones. A one-way ANOVA revealed group differences $\left(F_{(2,64)}=3.97, P=0.02\right)$, and post-hoc analysis using Fisher's PLSD revealed a significant difference $(P<0.05)$ between the Control group and the Sleep/Handle group. No difference was found between the Control group and the Awake/Handle group $(P>$ 0.8 , n.s.). Overall, handling during the sleep phase produced pervasive deficits in contextual and tone fear. On the other hand, handling during the awake phase produced selective deficits in contextual fear.

\section{Experiment 2}

Training was identical to Exp 1, although a 4-min baseline period was used. After training, mice were given two injections of $8 \mathrm{mg} /$ $\mathrm{kg}$ D-amphetamine hemisulfate (Sigma-Aldrich), i.p., or $10 \mathrm{~mL} / \mathrm{kg}$ saline solution (Fig. 1C). The Sleep/Amph (sleep-deprived) group received amphetamine immediately after training, at the start of their main sleep phase, and $4 \mathrm{~h}$ later. The Sleep/Sal control group received saline at the same times. To control for effects of amphetamine, the Awake/Amph and Awake/Sal groups were administered amphetamine and saline, respectively, at the start of the main wake phase and $4 \mathrm{~h}$ later. A two-way ANOVA revealed no group differences during training $\left(F_{(2,64)}<1\right.$, n.s.), and all groups exhibited significant learning $\left(F_{(9,64)}=17.5, P<0.001\right.$; Fig. $\left.3 \mathrm{~A}\right)$.

Contextual fear was examined $72 \mathrm{~h}$ after training (as in Exp 1). Amphetamine failed to produce any deficit in contextual fear conditioning when given during either the sleep or awake phase (Fig. 3B). A two-way ANOVA revealed no main effect of drug $\left(F_{(1,61)}<1\right.$, n.s.) or phase $\left(F_{(1,61)}<1\right.$, n.s. $)$.

As in $\operatorname{Exp} 1$, a tone test was conducted $30 \mathrm{~min}$ after the context test. Amphetamine failed to produce any deficit in cued fear conditioning when given during the sleep or awake phase (Fig. 3C). Freezing during the 2-min baseline was subtracted from the average freezing to the three tones. A two-way ANOVA re- then given no handling ("non-sleep-deprived") or $5 \mathrm{~h}$ of handling either immediately after training ("0-5 h") or $5 \mathrm{~h}$ later ("5-10 h"). This protocol raises a number of issues. First, all mice experienced some sleep deprivation because sleep was interrupted to give training and testing. Therefore, any sleep deprivation effect observed is additive with a sleep deprivation baseline. Second, deprivation in the $0-5 \mathrm{~h}$ group did not span the entire sleep period, nor did it target a specific sleep period, since handling was given $5 \mathrm{~h}$ after the sleep phase began. Third, the $5-10 \mathrm{~h}$ group did not target sleep or awake periods specifically, as handling overlapped both phases. Fourth, the study did not have a proper control group to examine the effects of handling alone on the memory impairment (i.e., handling only in the awake phase). Due to these confounds, the results of the Graves et al. study are problematic.

Our findings suggest that gentle handling is not a selective method of sleep deprivation. First, extensive handling during the entire sleep phase appears to produce nonspecific impairment. Second, with regard to contextual memory, handling during the awake phase can induce the same magnitude of amnesia as sleep deprivation. This suggests that there are non-sleep-related consequences of extensive handling (e.g., stress, interference, etc.) that may impair memory. This interpretation is consistent with
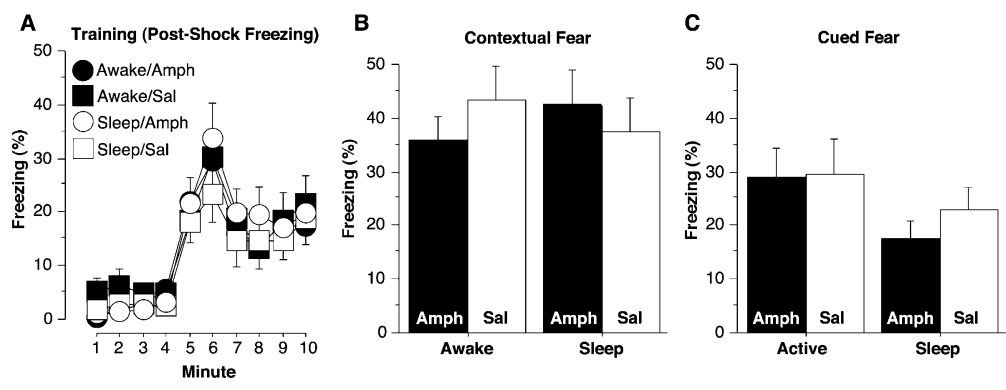

Figure 3. (A) Training: After a 4-min habituation period, mice were given one tone-shock pairing and were left in the chambers for a total of $10 \mathrm{~min}$. Freezing (mean percent time \pm SEM) is depicted for each minute of the training session. All groups exhibited robust learning, and there were no group dfferences. ( $B$ ) Contextual Fear: Seventy-two hours post-training, mice were given a 5-min contextual fear test. Freezing (mean percent time \pm SEM) for the 5-min test is depicted. There were no differences between the groups, suggesting that sleep-deprivation by amphetamine did not induce deficits in contextual fear memory. (C) Cued Fear: Thirty minutes after the context test, mice were brought to a novel context for a 5-min cued fear test. After a 2-min baseline period, the training tone was presented three times across $3 \mathrm{~min}$. Cued fear is depicted as freezing (mean percent time \pm SEM) during the baseline subtracted from the average of freezing to the three tones. There were no group differences. 
prior critiques of sleep deprivation studies, which found that seemingly benign handling methods can induce health problems and an elevated stress response (Murison et al. 1982; Mullington et al. 2009). Thus, this common method of sleep deprivation is confounded by non-sleep-related effects and is not an ideal tool for investigating the relationship between sleep and memory.

To explore an alternative to handling, we examined pharmacological sleep deprivation. We administered two high doses (8 $\mathrm{mg} / \mathrm{kg}$ ) of amphetamine immediately after training and $4 \mathrm{~h}$ into the sleep phase, and found that this method failed to produce impairments of contextual or cued fear. One possibility for the lack of impairment is that the drug did not actually deprive the animals of sleep. This is unlikely, as this high dose produces insomnia and hyperlocomotion (Ervin et al. 1981; Anagnostaras and Robinson 1996; Anagnostaras et al. 2002b; Wood and Anagnostaras 2009) and D-amphetamine has a long, although variable, half-life (3.5$4.2 \mathrm{~h}$ in acidic urine) (Buxton 2006). Another possibility is that amphetamine had a positive effect on consolidation that counteracted the deprivation impairment. This also seems unlikely, as we have found pervasive memory deficits using this dose of amphetamine (alone) during training (Wood and Anagnostaras 2009). Alternatively, these data could indicate that sleep is not involved in memory consolidation. In this manner, stimulant-induced sleep deprivation may be unique in that it does not produce an amnesic stress response. Nonetheless, the unknown effects of amphetamine on stress and consolidation suggest that stimulants are not a viable method to investigate the relationship between sleep and memory.

Sleep deprivation itself may be inherently stressful, perhaps due to a build up of a sleep homeostatic drive. Because sleep is typically treated as a drive (need), governed by homeostatic factors, a "sleep pressure" is thought to build up, which is suggested to be aversive and stressful (Bolles 1967). If this is the case, no sleep deprivation method will satisfactorily dissociate the effects of stress and lack of sleep on cognitive impairment. Therefore, we favor using a more naturalistic paradigm to investigate the consolidation process that may occur during natural sleep. In a separate study published elsewhere, we explored this using a novel rodent paradigm (Cai et al. 2009). We compared 12and 24-h delay intervals to control for time passage and circadian effects. We controlled for differences in circadian activity by selecting training and testing times within the transition interval from active to wake periods. That study found that sleep plays an important and selective role in contextual fear conditioning, whereby contextual memory is enhanced only when tested after a sleep period. This approach provides a useful way to examine sleep-induced memory enhancement, while avoiding confounds associated with the sleep-deprivation paradigm.

The current data suggest that it is problematic to use sleep deprivation as a way of exploring the role of natural sleep in memory consolidation. Although gentle handling produced amnesia, it was not specific to the sleep phase, making it difficult to disentangle the cause for the memory impairments. Nonetheless, the effects of sleep deprivation may be intrinsically interesting, as sleep deprivation is so prevalent in modern society (Bonnet and Arand 1995; Arnold et al. 1997; Anderson and Horne 2008). However, rather than extensive handling of animals, we would encourage utilization of more naturalistic modeling of sleep deprivation.

\section{Acknowledgments}

This work was supported by a Hellman fellowship (S.G.A.) and a Chancellor's Interdisciplinary Collaboratories Grant (T.S., D.J.C., S.G.A.). We thank Michael Gorman for resources and thoughtful discussion, and Kelly Cavanaugh, Anne Marie Ferruzi, Steven Lew, Allen Kim, Julie Wall, Angela Kuzara, Lily Marouf, Nicole Garces,
Erin Krizy, Kristin Wisner, Kristin Landa, Emily Man, Briana Colorado, and Jonathan Ung, for tireless hours of gentle handling.

\section{References}

Anagnostaras SG, Robinson TE. 1996. Sensitization to the psychomotor stimulant effects of amphetamine: Modulation by associative learning Behav Neurosci 110: 1397-1414.

Anagnostaras SG, Maren S, Fanselow MS. 1999. Temporally graded retrograde amnesia of contextual fear after hippocampal damage in rats: Within-subjects examination. J Neurosci 19: 1106-1114.

Anagnostaras SG, Josselyn SA, Frankland PW, Silva AJ. 2000. Computerassisted behavioral assessment of Pavlovian fear conditioning in mice. Learn Mem 7: 58-72.

Anagnostaras SG, Gale GD, Fanselow MS. 2001. Hippocampus and contextual fear conditioning: Recent controversies and advances. Hippocampus 11: 8-17.

Anagnostaras SG, Gale GD, Fanselow MS. 2002a. The hippocampus and Pavlovian fear conditioning: Reply to Bast. Hippocampus 12: $561-565$.

Anagnostaras SG, Schallert T, Robinson TE. 2002b. Memory processes governing amphetamine-induced psychomotor sensitization. Neuropsychopharmacology 26: 703-715.

Anderson C, Horne JA. 2008. Do we really want more sleep? A populationbased study evaluating the strength of desire for more sleep. Sleep Med 9: 184-187.

Arnold PK, Hartley LR, Corry A, Hochstadt D, Penna F, Feyer AM. 1997. Hours of work, and perceptions of fatigue among truck drivers. Accid Anal Prev 29: 471-477.

Bolles RC. 1967. Theory of motivation. Harper \& Row, New York.

Bonnet MH, Arand DL. 1995. We are chronically sleep deprived. Sleep 18: 908-911.

Buxton ILO. 2006. Appendix I Principles of prescription order writing and patient compliance. In Goodman \& Gilman's The pharmacological basis of therapeutics, 11th ed. (eds. LL Bruton et al.). McGraw-Hill, New York.

Cai DJ, Shuman T, Gorman MR, Sage JR, Anagnostaras SG. 2009. Sleep selectively enhances hippocampus-dependent memory in mice. Behav Neurosci 123: 713-719.

Campbell IG, Guinan MJ, Horowitz JM. 2002. Sleep deprivation impairs long-term potentiation in rat hippocampal slices. J Neurophysiol 88: 1073-1076.

Carter N, Ulfberg J, Nystrom B, Edling C. 2003. Sleep debt, sleepiness and accidents among males in the general population and male professional drivers. Accid Anal Prev 35: 613-617.

Chaudhury D, Colwell CS. 2002. Circadian modulation of learning and memory in fear-conditioned mice. Behav Brain Res 133: 95-108.

Crawley JN, Belknap JK, Collins A, Crabbe JC, Frankel W, Henderson N, Hitzemann RJ, Maxson SC, Miner LL, Silva AJ, et al. 1997. Behavioral phenotypes of inbred mouse strains: Implications and recommendations for molecular studies. Psychopharmacology 132: 107-124.

Dement W, Levine S, Morden B, Conner R. 1968. Steroid responses to stress of rats deprived of REM sleep by water tank method. Psychophysiology 4: 394.

Ellenbogen JM, Hulbert JC, Stickgold R, Dinges DF, Thompson-Schill SL. 2006. Interfering with theories of sleep and memory: Sleep, declarative memory, and associative interference. Curr Biol 16: 1290-1294.

Ervin GN, Birkemo LS, Nemeroff CB, Prange AJ Jr. 1981. Neurotensin blocks certain amphetamine-induced behaviours. Nature 291: 73-76.

Frankland PW, Bontempi B, Talton LE, Kaczmarek L, Silva AJ. 2004. The involvement of the anterior cingulate cortex in remote contextual fear memory. Science 304: 881-883.

Gale GD, Anagnostaras SG, Godsil BP, Mitchell S, Nozawa T, Sage JR, Wiltgen B, Fanselow MS. 2004. Role of the basolateral amygdala in the storage of fear memories across the adult lifetime of rats. J Neurosci 24: 3810-3815.

Graves LA, Heller EA, Pack AI, Abel T. 2003. Sleep deprivation selectively impairs memory consolidation for contextual fear conditioning. Learn Mem 10: 168-176.

Horne JA, McGrath MJ. 1984. The consolidation hypothesis for REM sleep function: Stress and other confounding factors-a review. Biol Psychol 18: $165-184$.

Maren S, Anagnostaras SG, Fanselow MS. 1998. The startled seahorse: Is the hippocampus necessary for contextual fear conditioning? Trends Cogn Sci 2: 39-42.

Matynia A, Anagnostaras SG, Wiltgen BJ, Lacuesta M, Fanselow MS, Silva AJ. 2008. A high through-put reverse genetic screen identifies two genes involved in remote memory in mice. PLoS One 3: e2121. doi: 10.1371/ journal.pone.0002121.

McKenna BS, Meloy MJ, Wetherell L, Stricker J, Drummond SPA. 2009. Change in neural networks following total sleep deprivation and recovery sleep. Sleep (in press). 
Mullington JM, Haack M, Toth M, Serrador JM, Meier-Ewert HK. 2009. Cardiovascular, inflammatory, and metabolic consequences of sleep deprivation. Prog Cardiovasc Dis 51: 294-302.

Murison R, Ursin R, Coover GD, Lien W, Ursin H. 1982. Sleep-deprivation procedure produces stomach lesions in rats. Physiol Behav 29: 693-694.

Nishida M, Pearsall J, Buckner RL, Walker MP. 2009. REM sleep, prefrontal theta, and the consolidation of human emotional memory. Cereb Cortex 19: 1158-1166.

Plihal W, Krug R, Pietrowsky R, Fehm HL, Born J. 1996. Corticosteroid receptor mediated effects on mood in humans. Psychoneuroendocrinology 21: $515-523$.

Quinn JJ, Ma QD, Tinsley MR, Koch C, Fanselow MS. 2008. Inverse temporal contributions of the dorsal hippocampus and medial prefrontal cortex to the expression of long-term fear memories. Learn Mem 15: 368-372.

Rechtschaffen A, Bergmann BM, Everson CA, Kushida CA, Gilliland MA. 1989. Sleep deprivation in the rat: I. Conceptual issues. Sleep 12: 1-4.

Rickard TC, Cai DJ, Rieth CA, Jones J, Ard MC. 2008. Sleep does not enhance motor sequence learning. J Exp Psychol Learn Mem Cogn 34: 834-842.
Roehrs T, Timms V, Zwyghuizen-Doorenbos A, Buzenski R, Roth T. 1990. Polysomnographic, performance, and personality differences of sleepy and alert normals. Sleep 13: 395-402.

Sapolsky RM. 2004. Why zebras don't get ulcers, 3rd ed. Holt, New York.

Smith C. 1985. Sleep states and learning: A review of the animal literature. Neurosci Biobehav Rev 9: 157-168.

Squire LR, Alvarez P. 1995. Retrograde amnesia and memory consolidation: A neurobiological perspective. Curr Opin Neurobiol 5: 169-177.

Van Hulzen ZJ, Coenen AM. 1979. Selective deprivation of paradoxical sleep and consolidation of shuttle-box avoidance. Physiol Behav 23: 821-826.

Vertes RP, Eastman KE. 2000. The case against memory consolidation in REM sleep. Behav Brain Sci 23: 867-876, discussion 904-1121.

Wood SC, Anagnostaras SG. 2009. Memory and psychostimulants: Modulation of Pavlovian fear conditioning by amphetamine in C57BL/ 6 mice. Psychopharmacology 202: 197-206.

Received June 17, 2009; accepted in revised form July 31, 2009. 


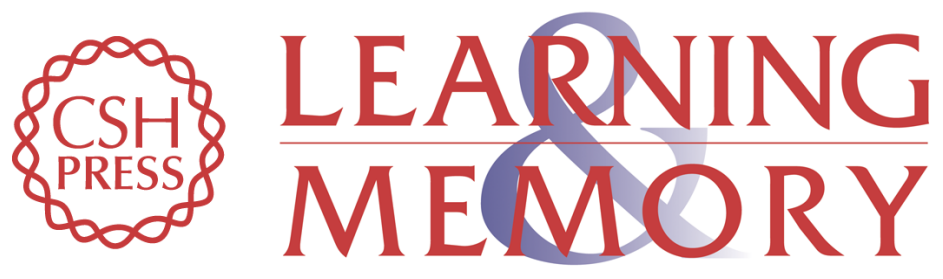

\section{Sleep deprivation and Pavlovian fear conditioning}

Denise J. Cai, Tristan Shuman, Elizabeth M. Harrison, et al.

Learn. Mem. 2009, 16:

Access the most recent version at doi:10.1101//m.1515609

References This article cites 36 articles, 6 of which can be accessed free at: http://learnmem.cshlp.org/content/16/10/595.full.html\#ref-list-1

License

Email Alerting Receive free email alerts when new articles cite this article - sign up in the box at the Service top right corner of the article or click here. 